\title{
Pharmacological stress: a useful exercise?
}

\author{
E. E. van der Wall
}

Published online: 15 January 2009

(C) The Author(s) 2009. This article is published with open access at Springerlink.com

Over the past years cardiovascular magnetic resonance (CMR) imaging has been increasingly used to detect the presence of coronary artery disease and to assess its functional consequences to the myocardium [1]. Several approaches have been applied to detect coronary artery disease with CMR including direct visualization of coronary arteries and bypass grafts [24] (magnetic resonance coronary angiography), the characterization of myocardial tissue [5-8] (delayed contrast enhancement) or the visualization of the effects of induced ischemia [9-17] (wall motion analysis or perfusion measurements). The latter is particularly valuable in clinical decision making since the detection of epicardial coronary luminal narrowing alone does not necessarily predict its hemodynamic consequences to the underlying myocardium.

In the last decades, pharmacological stress has been extensively evaluated as an alternative stress method and is particularly advised to those patients who are not able to perform adequately either due to limited exercise capability or a disabling disease. With the development of rapid gradient systems and the routine application of advanced CMR scanner systems, it has

Editorial comment to the paper of Karamitsos et al. (doi: 10.1007/s10554-008-9392-3).

E. E. van der Wall ( $₫)$

Department of Cardiology, Leiden University Medical Center, P.O. Box 9600, Leiden, The Netherlands

e-mail: e.e.van_der_wall@lumc.nl become possible to perform cine imaging of the heart at rest and under stress conditions with CMR. Since space is limited within the MR scanner bore and patient movement impairs image quality, pharmacological stress is preferred for CMR imaging. Research efforts have been focused on the definition of the clinical role of magnetic resonance pharmacological stress for the detection of inducible wall motion abnormalities, preferably using dobutamine stress magnetic resonance (DSMR) [18-30]. High-dose DSMR proved to be highly accurate for the detection of inducible wall motion abnormalities and its usefulness for determination of patient prognosis has been shown [18-24]. DSMR at low-dose dobutamine levels was found to be highly predictive of functional improvement of resting wall motion abnormalities after coronary revascularization procedures (detection of viable myocardium) [25-27].

For induction of ischemic wall motion abnormalities, adenosine/dipyridamole or dobutamine are routinely used and the outcome is often considered alike and interchangeable. In a landmark study by Paetsch et al. [31], the results of a direct comparison of dobutamine stress CMR, adenosine stress CMR and adenosine stress CMR perfusion as assessed during a single, combined examination with all stress tests were evaluated against coronary angiography as the standard of reference. This study proved that dobutamine was superior to adenosine stress for the detection of inducible wall motion abnormalities related to the presence of epicardial coronary 
stenoses $>50 \%$, with DSMR and adenosine stress CMR, yielding an overall diagnostic accuracy of 86 and $58 \%$, respectively. Only for the detection of coronary artery stenosis $>75 \%$, a reasonably good diagnostic accuracy of adenosine stress CMR was found. Based on this study, adenosine was not considered suitable the detection of inducible wall motion abnormalities resulting from epicardial coronary stenoses. This finding is physiologically quite understandable as adenosine is a vasodilatory agent not necessarily inducing an ischemic response but rather a maldistribution of flow [32, 33]. This phenomenon explains the absence of wall motion abnormalities in the absence of true myocardial ischemia. As a result, adenosine in conjunction with advanced CMR imaging might be better suited for direct assessment of perfusion abnormalities rather than detection of wall motion abnormalities.

Several studies have addressed the value of adenosine in conjunction with CMR imaging in terms of safety, diagnostic accuracy and prognosis [34-39]. Recently, Greenwood et al. [40] determined the safety and diagnostic accuracy of adenosine-stress CMR perfusion imaging early after acute ST elevation myocardial infarction (STEMI) compared with standard exercise tolerance testing in 35 patients admitted with first acute STEMI. All patients underwent a CMR imaging protocol which included rest and adenosine-stress perfusion, viability, and cardiac functional assessment. Adenosine stress CMR imaging was well tolerated in all patients and no complications occurred. CMR was more sensitive and more accurate than exercise testing for detecting significant coronary artery stenosis, and more sensitive for predicting revascularization. It was concluded that adenosine-stress CMR imaging is a safe procedure early after acute STEMI and identifies patients with significant coronary stenosis more accurately than conventional exercise tolerance testing. Pilz et al. [41] recently showed that a normal adenosine stress CMR predicted a very low cardiac event rate and an excellent 1-year prognosis in 128 patients with suspected coronary artery disease. Adenosine-stress CMR imaging may therefore serve as a reliable noninvasive gatekeeper in reducing the number of redundant coronary angiographies.

In the present issue of the International Journal of Cardiovascular Imaging, Karamitsos et al. [42] determined the safety and tolerance of adenosine stress CMR first-pass perfusion imaging in 351 patients with suspected or known coronary artery disease. In total, 233 patients $(76 \%)$ were found to have significant coronary artery disease of whom 128 patients $(36 \%)$ had multi-vessel disease. There were no deaths, myocardial infarctions, or episodes of bronchospasm during the CMR study. Transient second (Mobitz II) or third-degree atrioventricular block occurred in 27 patients $(8 \%)$. There were no sustained episodes of advanced atrioventricular block. Patients on beta-blocking agents or calciumchannel antagonists were not at increased risk for atrioventricular block. Transient chest pain was the most common side effect in 199 subjects (57\%). The present study differs from previous studies by (1) including a large percentage $(86 \%)$ of patients with angiographic data, (2) a prolonged infusion time ( 4 min instead of $3 \mathrm{~min}$ routinely), and (3) more importantly, the procedure was safe in patients with multi-vessel disease. A limitation of the study was the rather short follow-up time of $1 \mathrm{~h}$ after administration of adenosine. However, given the very short half-time $(<10 \mathrm{~s})$ of adenosine, major side effects beyond one hour of administration are not to be expected. Besides, aminophylline is a very useful and efficient antidote to adenosine.

To summarize, it can be concluded that adenosine is a very suitable agent for stress CMR perfusion imaging, as it is well-tolerated and safe even in patients with severe coronary artery disease. Consequently, adenosine stress CMR imaging is a valuable adjunctive modality in assessing myocardial perfusion abnormalities with prognostic implications in patients with suspected and known coronary artery disease.

Open Access This article is distributed under the terms of the Creative Commons Attribution Noncommercial License which permits any noncommercial use, distribution, and reproduction in any medium, provided the original author(s) and source are credited.

\section{References}

1. van der Wall EE, Vliegen HW, de Roos A, Bruschke AV (1995) Magnetic resonance imaging in coronary artery disease. Circulation 92:2723-2739

2. Langerak SE, Vliegen HW, de Roos A et al (2002) Detection of vein graft disease using high-resolution magnetic resonance angiography. Circulation 105:328-333

3. Salm LP, Vliegen HW, Langerak SE et al (2005) Evaluation of saphenous vein coronary artery bypass graft flow by 
cardiovascular magnetic resonance. J Cardiovasc Magn Reson 7:631-637

4. Vliegen HW, Doornbos J, de Roos A, Jukema JW, Bekedam MA, van der Wall EE (1997) Value of fast gradient echo magnetic resonance angiography as an adjunct to coronary arteriography in detecting and confirming the course of clinically significant coronary artery anomalies. Am J Cardiol 79:773-776

5. van der Wall EE, van Dijkman PR, de Roos A et al (1990) Diagnostic significance of gadolinium-DTPA (diethylenetriamine penta-acetic acid) enhanced magnetic resonance imaging in thrombolytic treatment for acute myocardial infarction: its potential in assessing reperfusion. Br Heart $\mathrm{J}$ 63:12-17

6. van Dijkman PR, van der Wall EE, de Roos A et al (1991) Acute, subacute, and chronic myocardial infarction: quantitative analysis of gadolinium-enhanced MR images. Radiology 180:147-151

7. van Rugge FP, Boreel JJ, van der Wall EE et al (1991) Cardiac first-pass and myocardial perfusion in normal subjects assessed by sub-second Gd-DTPA enhanced MR imaging. J Comput Assist Tomogr 15:959-965

8. Nijveldt R, Beek AM, Hirsch A et al (2008) 'No-reflow' after acute myocardial infarction: direct visualisation of microvascular obstruction by gadolinium-enhanced CMR. Neth Heart J 16:179-181

9. Buller VG, van der Geest RJ, Kool MD, van der Wall EE, de Roos A, Reiber JH (1997) Assessment of regional left ventricular wall parameters from short axis magnetic resonance imaging using a three-dimensional extension to the improved centerline method. Invest Radiol 32:529-539

10. Holman ER, Buller VG, de Roos A et al (1997) Detection and quantification of dysfunctional myocardium by magnetic resonance imaging. A new three-dimensional method for quantitative wall-thickening analysis. Circulation 95:924-931

11. Bax JJ, Lamb H, Dibbets P, Pelikan H et al (2000) Comparison of gated single-photon emission computed tomography with magnetic resonance imaging for evaluation of left ventricular function in ischemic cardiomyopathy. Am J Cardiol 86:1299-1305

12. van der Wall EE, Heidendal GA, den Hollander W, Westera G, Roos JP (1980) I-123 labeled hexadecenoic acid in comparison with thallium-201 for myocardial imaging in coronary heart disease. A preliminary study. Eur J Nucl Med 5:401-405

13. Braun S, van der Wall EE, Emanuelsson S, Kobrin I (1996) Effects of a new calcium antagonist, mibefradil (Ro 40-5967), on silent ischemia in patients with stable chronic angina pectoris: a multicenter placebo-controlled study. The mibefradil international study group. J Am Coll Cardiol 27:317-322

14. van Lennep JE, Westerveld HT, van Lennep HW, Zwinderman AH, Erkelens DW, van der Wall EE (2000) Apolipoprotein concentrations during treatment and recurrent coronary artery disease events. Arterioscler Thromb Vasc Biol 20:2408-2413

15. Tulevski II, Hirsch A, Sanson BJ et al (2001) Increased brain natriuretic peptide as a marker for right ventricular dysfunction in acute pulmonary embolism. Thromb Haemost 86:1193-1196
16. Bavelaar-Croon CD, Pauwels EK, van der Wall EE (2001) Gated single-photon emission computed tomographic myocardial imaging: a new tool in clinical cardiology. Am Heart J 141:383-390

17. Bavelaar-Croon CD, Kayser HW, van der Wall EE et al (2000) Left ventricular function: correlation of quantitative gated SPECT and MR imaging over a wide range of values. Radiology 217:572-575

18. van Rugge FP, Holman ER, van der Wall EE et al (1993) Quantitation of global and regional left ventricular function by cine magnetic resonance imaging during dobutamine stress in normal human subjects. Eur Heart J 14:456-463

19. van Rugge FP, van der Wall EE, Spanjersberg SJ et al (1994) Magnetic resonance imaging during dobutamine stress for detection and localization of coronary artery disease. Quantitative wall motion analysis using a modification of the centerline method. Circulation 90:127-138

20. Pluim BM, Lamb HJ, Kayser HW et al (1998) Functional and metabolic evaluation of the athlete's heart by magnetic resonance imaging and dobutamine stress magnetic resonance spectroscopy. Circulation 97:666-672

21. Tulevski II, Lee PL, Groenink M et al (2000) Dobutamineinduced increase of right ventricular contractility without increased stroke volume in adolescent patients with transposition of the great arteries: evaluation with magnetic resonance imaging. Int J Cardiovasc Imaging 16:471-478

22. Kuijpers D, Ho KY, van Dijkman PR, Vliegenthart R, Oudkerk M (2003) Dobutamine cardiovascular magnetic resonance for the detection of myocardial ischemia with the use of myocardial tagging. Circulation 107:1592-1597

23. Wahl A, Paetsch I, Roethemeyer S, Klein C, Fleck E, Nagel E (2004) High-dose dobutamine-atropine stress cardiovascular MR imaging after coronary revascularization in patients with wall motion abnormalities at rest. Radiology 233:210-216

24. Lubbers DD, Janssen CH, Kuijpers D et al (2008) The additional value of first pass myocardial perfusion imaging during peak dose of dobutamine stress cardiac MRI for the detection of myocardial ischemia. Int J Cardiovasc Imaging 24:69-76

25. Kaandorp TA, Lamb HJ, Bax JJ et al (2005) Prediction of beneficial effect of beta blocker treatment in severe ischaemic cardiomyopathy: assessment of global left ventricular ejection fraction using dobutamine stress cardiovascular magnetic resonance. Heart 91:1471-1472

26. Dall'Armellina E, Morgan TM, Mandapaka S et al (2008) Prediction of cardiac events in patients with reduced left ventricular ejection fraction with dobutamine cardiovascular magnetic resonance assessment of wall motion score index. J Am Coll Cardiol 52:279-286

27. Paetsch I, Jahnke C, Fleck E, Nagel E (2005) Current clinical applications of stress wall motion analysis with cardiac magnetic resonance imaging. Eur $\mathrm{J}$ Echocardiogr $6: 317-326$

28. Molhoek SG, Bax JJ, Bleeker GB et al (2004) Comparison of response to cardiac resynchronization therapy in patients with sinus rhythm versus chronic atrial fibrillation. Am J Cardiol 94:1506-1509

29. Ypenburg C, van der Wall EE, Schalij MJ, Bax JJ (2008) Imaging in cardiac resynchronisation therapy. Neth Heart J 16(Suppl 1):S36-S40 
30. Nemes A, Geleijnse ML, van Geuns RJ et al (2008) Dobutamine stress MRI versus threedimensional contrast echocardiography: it's all Black and White. Neth Heart J 16:217-218

31. Paetsch I, Jahnke C, Wahl A et al (2004) Comparison of dobutamine stress magnetic resonance, adenosine stress magnetic resonance, and adenosine stress magnetic resonance perfusion. Circulation 110:835-842

32. Wilson RF, Wyche K, Christensen BV, Zimmer S, Laxson DD (1990) Effects of adenosine on human coronary arterial circulation. Circulation 82:1595-1606

33. Cerqueira MD, Verani MS, Schwaiger M, Heo J, Iskandrian AS (1994) Safety profile of adenosine stress perfusion imaging: results from the Adenoscan Multicenter Trial Registry. J Am Coll Cardiol 23:384-389

34. Ingkanisorn WP, Kwong RY, Bohme NS et al (2006) Prognosis of negative adenosine stress magnetic resonance in patients presenting to an emergency department with chest pain. J Am Coll Cardiol 47:1427-1432

35. Klem I, Heitner JF, Shah DJ et al (2006) Improved detection of coronary artery disease by stress perfusion cardiovascular magnetic resonance with the use of delayed enhancement infarction imaging. J Am Coll Cardiol 47:1630-1638

36. Bernhardt P, Steffens M, Kleinertz K et al (2006) Safety of adenosine stress magnetic resonance imaging using a mobile cardiac magnetic resonance system. J Cardiovasc Magn Reson 8:475-478
37. Bernhardt P, Levenson B, Engels T, Strohm O (2006) Contrast-enhanced adenosine-stress magnetic resonance imaging-feasibility and practicability of a protocol for detection or exclusion of ischemic heart disease in an outpatient setting. Clin Res Cardiol 95:461-467

38. Jahnke C, Nagel E, Gebker R et al (2007) Prognostic value of cardiac magnetic resonance stress tests: adenosine stress perfusion and dobutamine stress wall motion imaging. Circulation 115:1769-1776

39. Thygesen K, Alpert JS, White HD (2007) Universal definition of myocardial infarction; joint ESC/ACCF/AHA/ WHF Task Force for the redefinition of myocardial infarction. Eur Heart J 28:2525-2538

40. Greenwood JP, Younger JF, Ridgway JP, Sivananthan MU, Ball SG, Plein S (2007) Safety and diagnostic accuracy of stress cardiac magnetic resonance imaging vs exercise tolerance testing early after acute ST elevation myocardial infarction. Heart 93:1363-1368

41. Pilz G, Jeske A, Klos M et al (2008) Prognostic value of normal adenosine-stress cardiac magnetic resonance imaging. Am J Cardiol 101:1408-1412

42. Karamitsos TD, Arnold JR, Pegg TJ et al. (2008) Tolerance and safety of adenosine stress perfusion cardiovascular magnetic resonance imaging in patients with severe coronary artery disease. Int $\mathbf{J}$ Cardiovasc Imaging. doi: 10.1007/s10554-008-9392-3 